Check for updates

Cite this: Mater. Adv., 2020,

1, 1695

Received 12th May 2020,

Accepted 19th July 2020

DOI: 10.1039/d0ma00304b

rsc.li/materials-advances

\title{
Vapor phase infiltration of zinc oxide into thin films of cis-polyisoprene rubber $\dagger$
}

\author{
Julian Pilz, (D) ab Anna Maria Coclite (D) ${ }^{a}$ and Mark D. Losego (D) *b
}

\begin{abstract}
Elastomers are an important class of polymers for many applications. Often, additives are added to the polymer matrix of elastomers to promote vulcanization or enhance physical or chemical properties. In this study, vapor phase infiltration (VPI) is investigated for transforming unvulcanized cis-polyisoprene (from natural rubber) into an organic/inorganic hybrid material. Specifically, we examine single-cycle infiltration with diethylzinc (DEZ) and water to form infiltrated zinc oxide species. Interestingly, lowtemperature pre-heating of the cis-polyisoprene acutely affects the processes of infiltration, including diffusivity, maximum solubility, and chemical reactivity. We attribute these effects to a combination of film relaxation and oxidation. Independent of thermal pre-treatments, all infiltration processes exhibited consistent zinc oxide loading irrespective of purge time between the DEZ and water doses, indicating the presence of a strongly bound intermediate state between the DEZ precursor and the cis-polyisoprene polymer. Increasing infiltration process temperature accelerates diffusion and lowers the maximum solubility, in accordance with Fick's law and gas phase sorption equilibrium. Resulting organic-inorganic hybrid films show enhanced resistance to dissolution in toluene, a good solvent for the pure polymer.
\end{abstract}

\section{Introduction}

Cis-Polyisoprene is the main component of natural rubber. ${ }^{1}$ In commercial applications, cis-polyisoprene is often vulcanized (i.e. cross-linked; in the case of natural rubbers often driven by sulfur compounds) and different components such as activators, accelerators, or fillers ${ }^{2}$ are added to the polymer to achieve desired properties. Activators and accelerators lower the process temperatures and accelerate the vulcanization process. $\mathrm{ZnO}$ is widely used as an activator in rubber manufacturing. An even distribution in the polymer matrix as well as the morphology of ZnO particles is key to its effectiveness in modulating vulcanization. ${ }^{3,4}$ Fillers are added to reinforce physical properties (mechanical, electrical, optical,...) and prominent examples are carbon black ${ }^{5}$ and silica. ${ }^{6}$ Similar to activators and accelerators, the size and distribution of fillers impacts the resulting properties. ${ }^{7}$

As such, vulcanizates (i.e. cross-linked elastomer polymers with additives) are a prominent example of composite and often hybrid organic-inorganic materials. Polymers that make up these vulcanizates are a new opportunity for vapor phase infiltration (VPI), a solvent-free method for infusing inorganic materials into polymers. Unlike many other methods currently used, VPI incorporates the inorganic species homogeneously at

\footnotetext{
${ }^{a}$ Institute of Solid State Physics, NAWI Graz, Graz University of Technology, 8010 Graz, Austria

${ }^{b}$ School of Materials Science and Engineering, Georgia Institute of Technology, Atlanta, Georgia 30332,USA. E-mail: losego@gatech.edu

$\dagger$ Electronic supplementary information (ESI) available. See DOI: 10.1039/d0ma00304b
}

the atomic level, and the species may be chemically bound or unbound to the polymer host. ${ }^{8}$

VPI is capable of distributing the inorganic material uniformly inside polymers and the amount of loading can be tuned by infiltration hold times, pressures, and cycle numbers. ${ }^{9,10}$ While VPI originated from the atomic layer deposition (ALD) community and shares similar precursor chemistries, the process mechanisms are substantially different. In ALD, precursors follow self-limiting surface reactions on the exterior of a material. In VPI, the gas-phase precursors are expected to sorb into the material (polymer), diffuse throughout that material, and eventually become entrapped within the material through either chemical reactions or other means. The mechanism for entrapment is important as it determines whether VPI processing can be run as an equilibrium or non-equilibrium process and whether the inorganic species form primary chemical bonds to the polymer host. These final hybrid materials are intermixed organicinorganic hybrid structures with properties distinctly different from the original polymer. ${ }^{11,12}$ For example, VPI has been used to increase the toughness of spider silk, ${ }^{13}$ increase the electrical conductivity of semiconducting polymers, ${ }^{14}$ and increase the solvent stability and separation performance of membranes. ${ }^{15}$

A recent investigation examined the use of vapor phase infiltration to incorporate inorganic materials into block co-polymers containing a rubber (elastomeric) block. In this recent study, VPI with diethyl zinc and water was used to infiltrate $\mathrm{ZnO}$ into epoxidized and unepoxidized polystyrene-block-poly(1,4-isoprene) copolymers (PS-b-PI). ${ }^{16}$ The authors found that even PS- $b$-PI 
(lacking strong functional groups) were effective templates for selective infiltration of the polyisoprene block, attributing it to factors such as increased miscibility of DEZ in the polyisoprene block. However, a concrete mechanism of infiltration of polyisoprene has not been reported in literature, despite the technological importance of this polymer.

Depending on a polymer's chemical structure, different mechanisms of infiltration may happen. ${ }^{17}$ In the case of nonreactive polymers, precursor molecules can diffuse into the polymer matrix and become weakly entrapped by physisorption or steric hindrance. However, by applying long purges, these weakly bound precursors should diffuse out of the matrix, leaving no loading within the polymer. For polymers with reactive functional groups, precursor molecules chemically bind to the available reactive groups and are not removed by long purges. This mechanism may further lead to cross-linking of the polymer chains. It is unclear to what extent the alkene functional groups in polyisoprene may play in entrapping metalorganic precursors in a VPI process.

This study aims to elucidate the fundamental kinetic and chemical mechanisms of zinc oxide VPI into cis-polyisoprene using DEZ and water precursors. The results expand the currently limited knowledge about VPI in rubber and provide a new possible technical application for VPI in introducing inorganic constituents to rubber polymers.

\section{Experimental}

Cis-Polyisoprene was purchased from Sigma-Aldrich (431257, average $M_{\mathrm{w}} \sim 38000$ by GPC, made from natural rubber). The purity of the polyisoprene was investigated with ATR-FTIR, which did not reveal any obvious impurities such as phosphates (see Fig. S1, ESI $\dagger$ ). 2 wt $\%$ solutions were prepared in toluene (Sigma-Aldrich) and stirred overnight. Thin films of polyisoprene (thickness $78 \pm 2 \mathrm{~nm}$ ( $n=100)$ after coating) were deposited on single-side polished $\mathrm{Si}$ wafers (p-type, WRS Materials) and glass slides by spin coating (10 s, $2000 \mathrm{rpm})$. No cleaning procedures were applied to the substrates prior to coating except for nitrogen flow. Pre-heating of the films was performed at $80{ }^{\circ} \mathrm{C}$ on a hot plate in air (thickness after $5 \mathrm{~h}$ preheating $68 \pm 6 \mathrm{~nm}(n=180)$, thickness after $24 \mathrm{~h}$ pre-heating $47 \pm 6 \mathrm{~nm}(n=100))$. Note that the glass transition temperature for this polymer is around $-64{ }^{\circ} \mathrm{C} .{ }^{18}$

Vapor phase infiltration (VPI) of the polymer films was performed in a custom-built system described earlier, ${ }^{15}$ and was controlled via a tree-based control software. ${ }^{19}$ The chamber was operated at a temperature of 60,80 , or $100{ }^{\circ} \mathrm{C}$. Diethylzinc (STREM Chemicals, 95\% purity, DANGER: pyrophoric) was used as the metalorganic precursor, deionized water as the oxidizing coreactant, and nitrogen (99.995\% purified from air) as the purging gas (flow rate $250 \mathrm{sccm}$ ). One cycle of VPI was applied to the polymer films which consisted of purging for $3600 \mathrm{~s}$ (to release residual water and other vapors trapped within the polymer), pump down to base pressure ( $\sim 60$ mTorr $)$, chamber isolation, DEZ dose for $1 \mathrm{~s}$ (through a valve with $C_{\mathrm{v}}=0.27$, providing a chamber pressure of $\sim 0.2$ Torr DEZ), hold in this static DEZ atmosphere for $20 \mathrm{~s}$ to $7200 \mathrm{~s}$, purge for $300 \mathrm{~s}$, pump down, chamber isolation, water dose for $5 \mathrm{~s}$ (reaching $\sim 2$ Torr $\mathrm{H}_{2} \mathrm{O}$ ), hold in this static $\mathrm{H}_{2} \mathrm{O}$ atmosphere for $1800 \mathrm{~s}$, and purge for $300 \mathrm{~s}$. For investigating the influence of purge time, the DEZ hold was fixed at $800 \mathrm{~s}$ and the purge time after DEZ was varied from $100 \mathrm{~s}$ to $232200 \mathrm{~s}$ ( $\sim 2.5$ days).

Attenuated total reflectance infrared spectroscopy (ATR-FTIR) was performed to monitor the chemical changes of spin-coated films upon pre-heating and infiltration. For these studies, films were prepared on glass substrates to minimize background intensities. Spectra were collected on a Thermo Scientific ${ }^{\mathrm{TM}}$ Nicolet $^{\mathrm{TM}}$ iS5 FTIR spectrometer with an iD7 ATR accessory with a diamond crystal. The resolution was $4 \mathrm{~cm}^{-1}$ and the spectra were averaged over 128 scans.

Thicknesses and optical constants of pristine, infiltrated, and calcinated films were obtained by spectroscopic ellipsometry (SE; J. A. Woolam alpha-SE). Spectra were obtained in a wavelength range $380-900 \mathrm{~nm}$ at $70^{\circ}$ (additionally $75^{\circ}$ for calcinated films). The model to fit the data consisted of a (semi-infinite) Si substrate, $1.7 \mathrm{~nm}$ fixed native oxide, and a Cauchy layer with thickness, $A, B$, and $k$ as fit parameters. For better comparison of layer thickness and due to correlation of fit parameters, the generic oscillator library model for $\mathrm{ZnO}$ (Complete Ease 5.08 software) was used for calcinated films and only the thickness was fitted.

Inorganic loading within the polymer was determined with both X-ray fluorescence spectroscopy (XRF; Thermo Scientific Niton FXL FM-XRF) and calcination of the infiltrated films. XRF was used to measure the relative amount of $\mathrm{Zn}$ in the films after infiltration. For this purpose, the amplitude of the $\mathrm{Zn} \mathrm{K} \alpha$ peak at $8.637 \mathrm{keV}$ was obtained by fitting a Gaussian to the spectrum. Spectra were recorded in general metals mode with a measurement time of $30 \mathrm{~s}$. Infiltrated films were also calcined in a furnace (Barnstead Thermolyne 1400; ramp up to $650{ }^{\circ} \mathrm{C}$ for $20 \mathrm{~min}$, hold for $30 \mathrm{~min}$ ) to remove the polymeric template and leave only the $\mathrm{ZnO}$ fraction. This residual quantity of $\mathrm{ZnO}$ was then evaluated with spectroscopic ellipsometry.

X-ray photoelectron spectroscopy was conducted with a Thermo Scientifc K-Alpha system using a monochromatic Al-K $\alpha$ X-ray source $(1486.6 \mathrm{eV})$ with a $60^{\circ}$ incident angle and a $90^{\circ}$ emission collection geometry (pass energy $200 \mathrm{eV}$ ) for survey elemental analysis.

Zinc concentration depth profiles of the infiltrated polyisoprene films were measured with time-of-flight secondary ion mass spectroscopy (ToF-SIMS, IONTOF, 5 Series). SIMS spectra were collected using oxygen ion sputtering $(150 \mu \mathrm{m} \times 150 \mu \mathrm{m}$, $2 \mathrm{kV}$ accelerating voltage) and bismuth analyzer $(50 \mu \mathrm{m} \times 50 \mu \mathrm{m})$ beams. Positive polarity was used to detect the $\mathrm{Zn}+, \mathrm{Si}+$, and $\mathrm{C}+$ signals from the infiltrated polymer films.

Chemical stability was tested by immersing pre-heated and infiltrated films (on $\mathrm{Si}$ ) in $10 \mathrm{ml}$ of toluene. The thickness was monitored intermittently by ex situ spectroscopic ellipsometry.

\section{Results and discussion}

\section{A. Demonstration of DEZ $+\mathrm{H}_{2} \mathrm{O}$ VPI in cis-polyisoprene}

Fig. 1 illustrates that DEZ $+\mathrm{H}_{2} \mathrm{O}$ VPI can successfully infuse $\mathrm{ZnO}$ into cis-polyisoprene films. Fig. 1(a) shows an X-ray 

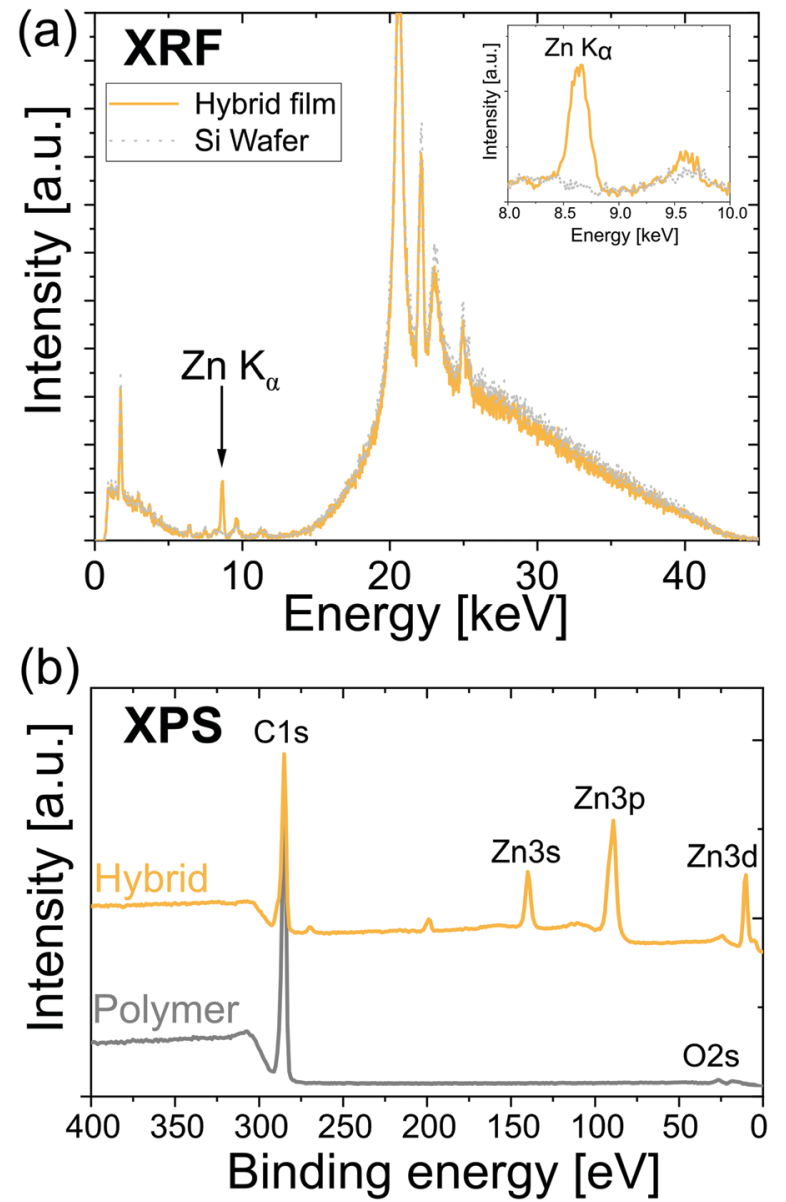

Fig. 1 Exemplary X-ray spectra of hybrid films demonstrating that $\mathrm{ZnO}$ was successfully loaded into the polyisoprene films. (a) X-ray fluorescence spectrum of a hybrid film and a blank Si wafer. The hybrid film displays a significant $\mathrm{Zn} \mathrm{K}_{\alpha}$ signal whereas all the other peaks stem either from the Si wafer or the sample holder. (b) X-ray photoelectron survey spectra (for low binding energy) from the surface of a polymer and hybrid film. The polymer film does not display impurities such as phosphorus and the hybrid film displays clear $\mathrm{Zn}$ signals. The spectra are stacked for clarity.

fluorescence spectrum (XRF) of a hybrid film and a blank Si wafer. The hybrid film shows a clear signal from the $\mathrm{Zn} \mathrm{K}_{\alpha}$ transition (enlarged spectrum shown in the inset), whereas all the other peaks stem either from the Si wafer or the sample holder (the fluorescence signal from organic elements $[Z<12]$ are undetectable by this XRF). The strong XRF signal is indicative of the $\mathrm{Zn}$ being infiltrated throughout the entire film and not just a single atomic layer on the surface. Investigations on the morphology of polyisoprene and hybrid films by atomic force microscopy (Fig. S2, ESI $\dagger$ ) support this argument as no major changes in the morphology are observed upon infiltration. Furthermore, no signs of phase separation between the organic and inorganic compounds are observed. Fig. 1(b) shows X-ray photoelectron spectra (XPS) of a polyisoprene and a hybrid film. The polyisoprene spectrum does not display significant amounts of impurities (except for oxygen due to oxidation; see next paragraph) and the spectrum of the hybrid film shows clear $\mathrm{Zn}$ signals. The shown spectra serve as a preview on the infiltration of polyisoprene; in the following paragraphs the infiltration mechanisms as well as the influence of the pretreatment of the polyisoprene films are examined in detail.

\section{B. Pre-heating of polyisoprene films}

Early in our investigations of the VPI process on polyisoprene, we noted some unusual variations in the polymer relaxation when being pre-heated on the hotplate. A pre-heating step is typically used after spin coating a polymer film to remove solvent and relax the polymer structure. For polyisoprene, we found that this relaxation process appears to occur over a fairly long period of time, potentially many hours. Fig. 2(a) plots the polyisoprene film thickness as a function of drying time $\left(80^{\circ} \mathrm{C}\right)$ for four independent trials (For trials 1-3, the thickness of the same individual film was monitored. For trial 4, each datapoint corresponds to the mean thickness of two individual samples, which were removed from the hotplate after the respective preheating times). While the thickness immediately after spin coating is around $80 \mathrm{~nm}$, all samples show a rapid thickness decrease for the first 5 to $10 \mathrm{~h}$. After about $20 \mathrm{~h}$, the thickness decrease slows and approaches a value between 40 and $50 \mathrm{~nm}$ (50 to $65 \%$ of the initial thickness). Initially, we attribute this reduction in thickness to a reduction in free volume of the polymer. Rapidly drying the polymer from solution via spin casting at room temperature often results in a metastable glass with high free volume. Even though the polymer is above $T_{\mathrm{g}}$ at room temperature, heating it should accelerate chain motion, relaxation, and reduce free volume, resulting in a reduction of the film thickness. However, as shown subsequently, it is likely that the changes in film thickness may be a combination of changes to both the free volume and polymer chemistry (e.g., an increase in cross-linking).

ATR-FTIR spectra were collected as a function of pre-heating time to interrogate potential chemical changes to the cis-polyisoprene films. The (scaled) IR spectra are shown in Fig. 2(b). For unheated films $(0 \mathrm{~h})$, the FTIR spectrum shows the characteristic $=\mathrm{C}-\mathrm{H}$ stretching, and $\mathrm{CH}_{3}$ and $\mathrm{CH}_{2}$ stretching and deformation modes of polyisoprene. ${ }^{20,21}$ The weak $\mathrm{C}=\mathrm{C}$ stretching mode $\left(\sim 1665 \mathrm{~cm}^{-1}\right)$ is not visible, which we attribute to the rather small thickness of the films. After $1 \mathrm{~h}$ of heating, an absorption peak attributed to $\mathrm{C}=\mathrm{O}$ stretching (ketones, $\sim 1714 \mathrm{~cm}^{-1}$ ) is apparent, indicative of partial oxidation. Longer heating durations (i.e. further oxidation) leads to more ketone groups as well as an increase in $\mathrm{O}-\mathrm{H}$ stretching absorbance. At $4 \mathrm{~h}$ heating, an additional peak appears, which can be attributed to carboxylic acids $\left(\sim 1766 \mathrm{~cm}^{-1}\right)$. Longer heating times lead to an increased absorbance in the $\mathrm{O}-\mathrm{H}$ and $\mathrm{C}=\mathrm{O}$ regions until a heating duration of $14 \mathrm{~h}$, after which the oxidation appears to reach saturation (i.e. no further increase in $\mathrm{O}-\mathrm{H}$ and $\mathrm{C}=\mathrm{O}$ absorbance). These studies suggest continued oxidation of the polymer from ketones to alcohols to carboxylic acids with longer heat treatments. Thermal treatment of unvulcanized and vulcanized elastomers has been a field of significant research. ${ }^{22-26}$ In a study by Colin et al. ${ }^{22}$ trans-polyisoprene is shown to oxidize in atmosphere similar to the behavior observed here via mechanisms such as chain-scission and cross-linking. Using molecular dynamics simulations, Li et $a .^{27}$ 

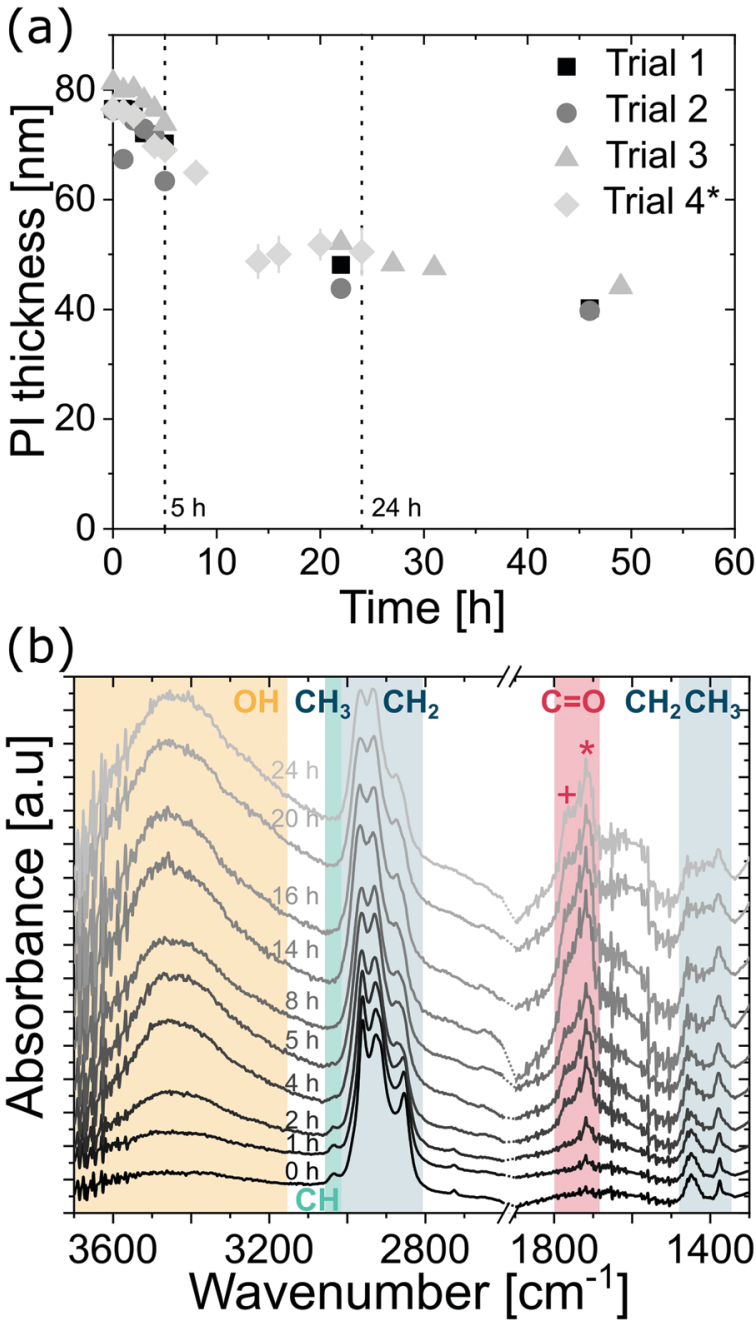

Fig. 2 (a) Thickness decrease as a function of time during pre-heating of polyisoprene thin films at $80^{\circ} \mathrm{C}$. Trial 1 to 3 constitute thickness data for the same films, respectively, whereas for trial 4 each datapoint constitutes the mean value of 2 individual samples. (b) ATR-FTIR absorbance spectra of spin coated polyisoprene films on glass. Films were pre-heated at $80^{\circ} \mathrm{C}$ for different durations (indicated by time in hours). Colored regions refer to $\mathrm{O}-\mathrm{H}$ stretching $\left(\sim 3400 \mathrm{~cm}^{-1}\right),=\mathrm{C}-\mathrm{H}$ stretching $\left(\sim 3036 \mathrm{~cm}^{-1}\right), \mathrm{CH}_{3}$ and $\mathrm{CH}_{2}$ stretching $\left(2800-2900 \mathrm{~cm}^{-1}\right), \mathrm{C}=\mathrm{O}$ stretching (+ and * referring to carboxylic acids $\left(\sim 1766 \mathrm{~cm}^{-1}\right)$ and ketones $\left(\sim 1714 \mathrm{~cm}^{-1}\right)$, respectively), and $\mathrm{CH}_{2}$ and $\mathrm{CH}_{3}$ deformation (1370-1450 $\mathrm{cm}^{-1}$ ). Spectra are scaled to their respective maximum value, offset, and cut to the regions where the main absorptions occur (strong absorption of glass substrate below $1300 \mathrm{~cm}^{-1}$ ). Dotted lines at the axis break serve as a guide for the eye.

show that (sulfur) cross-linking leads to shrinkage of cis-polyisoprene chains. While the exact mechanisms of oxidation and film shrinkage are difficult to ascertain, oxidation and subsequent cross-linking could be one factor in addition to polymer relaxation for the film shrinkage observed in Fig. 2(a).

\section{Quantifying inorganic loading}

Because pre-heating steps significantly affect the polyisoprene chemistry and structure, they are also expected to affect the infiltration process. To better understand this influence, we study infiltration of unheated, $5 \mathrm{~h}$ pre-heated (partially relaxed and oxidized), and $24 \mathrm{~h}$ pre-heated (close to fully relaxed and oxidized) films. Fig. 3 summarizes the variations in zinc oxide loading depending upon pre-heating conditions for VPI at $80{ }^{\circ} \mathrm{C}$ and DEZ hold times of $7200 \mathrm{~s}$ ( 5 individual samples per preheating condition). Most of the polyisoprene films pre-heated for $0 \mathrm{~h}$ and $5 \mathrm{~h}$ show a decrease in thickness $(-1.6 \%$ and $-4.3 \%$ on average, respectively) upon infiltration while most films pre-heated for $24 \mathrm{~h}$ show an increase in thickness $(+5.6 \%$ on average). Presuming that volume change is indicative of inorganic loading, these differences in film thickness upon infiltration suggest that the films pre-heated for $0 \mathrm{~h}$ or $5 \mathrm{~h}$ have less inorganic loading than the films heated for $24 \mathrm{~h}$. However, after calcining these films to leave just the inorganic $\mathrm{ZnO}$ component, we find the opposite trend. Fig. 3(b) plots this result, showing the $\mathrm{ZnO}$ layer thickness after calcination for each of the trials in Fig. 3(a). On average the polyisoprene films pre-heated for only $5 \mathrm{~h}$ have about twice the ZnO thickness $(\sim 8 \mathrm{~nm})$ as those pre-heated for $0 \mathrm{~h}$ or $24 \mathrm{~h}(\sim 4 \mathrm{~nm})$. While the swelling of polymer films is often used as an indicator for inorganic loading in VPI literature, ${ }^{11,17,28}$ it is not a direct measure of the mass loading, and as shown here, film swelling is not always a good indicator of inorganic loading. The noncorrelation of the swelling and the $\mathrm{ZnO}$ thickness after calcination is attributed to a competition between the relaxations/shrinking occurring within the film due to a reduction of the polymer's free volume (thickness decrease) with the swelling due to inorganic mass uptake (thickness increase).

These results suggest that spectroscopic ellipsometry is not always a reliable non-destructive characterization tool for assessing inorganic loading in VPI synthesized hybrid materials. Thus, we also explored the use of XRF as an alternative method for inorganic loading quantification. XRF has not previously had wide use in the VPI community. ${ }^{11}$ XRF is a non-destructive and fast (measurement times $\sim 1 \mathrm{~min}$ ) characterization technique, that can readily be used to provide relative quantities of inorganics within a hybrid material. (Note: absolute amounts can be measured by calibrating the XRF detector to standards; within the scope of this paper, relative amounts are sufficient, although good standards for infiltrated materials should be developed.) Fig. 3(c) plots the correlation of the measured XRF Zn $\mathrm{K}_{\alpha}$ peak height (of the hybrid film) against the calcined $\mathrm{ZnO}$ film thickness determined by spectroscopic ellipsometry in Fig. 3(b). Good correlation is found between these two methods, validating XRF's use for nondestructive quantification of Zn loading in VPI hybrid thin films.

\section{Kinetics of zinc oxide infiltration into cis-polyisoprene}

Next, we examine the kinetics of inorganic loading as a function of VPI process temperature $\left(60^{\circ} \mathrm{C}, 80^{\circ} \mathrm{C}\right.$, and $\left.100{ }^{\circ} \mathrm{C}\right)$. Fig. 4 plots the amount of zinc uptake (measured by XRF) into cis-polyisoprene during a 1-cycle VPI process for varying 0.2 Torr DEZ exposure times $(20 \mathrm{~s}$ to $4 \mathrm{~h})$. These $\mathrm{Zn}$ uptake plots are shown for both unheated (Fig. 4(a)), $5 \mathrm{~h}$ pre-heated (Fig. 4(b)) and $24 \mathrm{~h}$ pre-heated (Fig. 4(c)) cis-polyisoprene films. (Fig. S3 (ESI $\dagger$ ) plots the calcined ZnO film thickness as a consistent comparison).

When the cis-polyisoprene is not pre-heated prior to infiltration (Fig. 4(a)), the sorption behavior is consistent with standard models. 

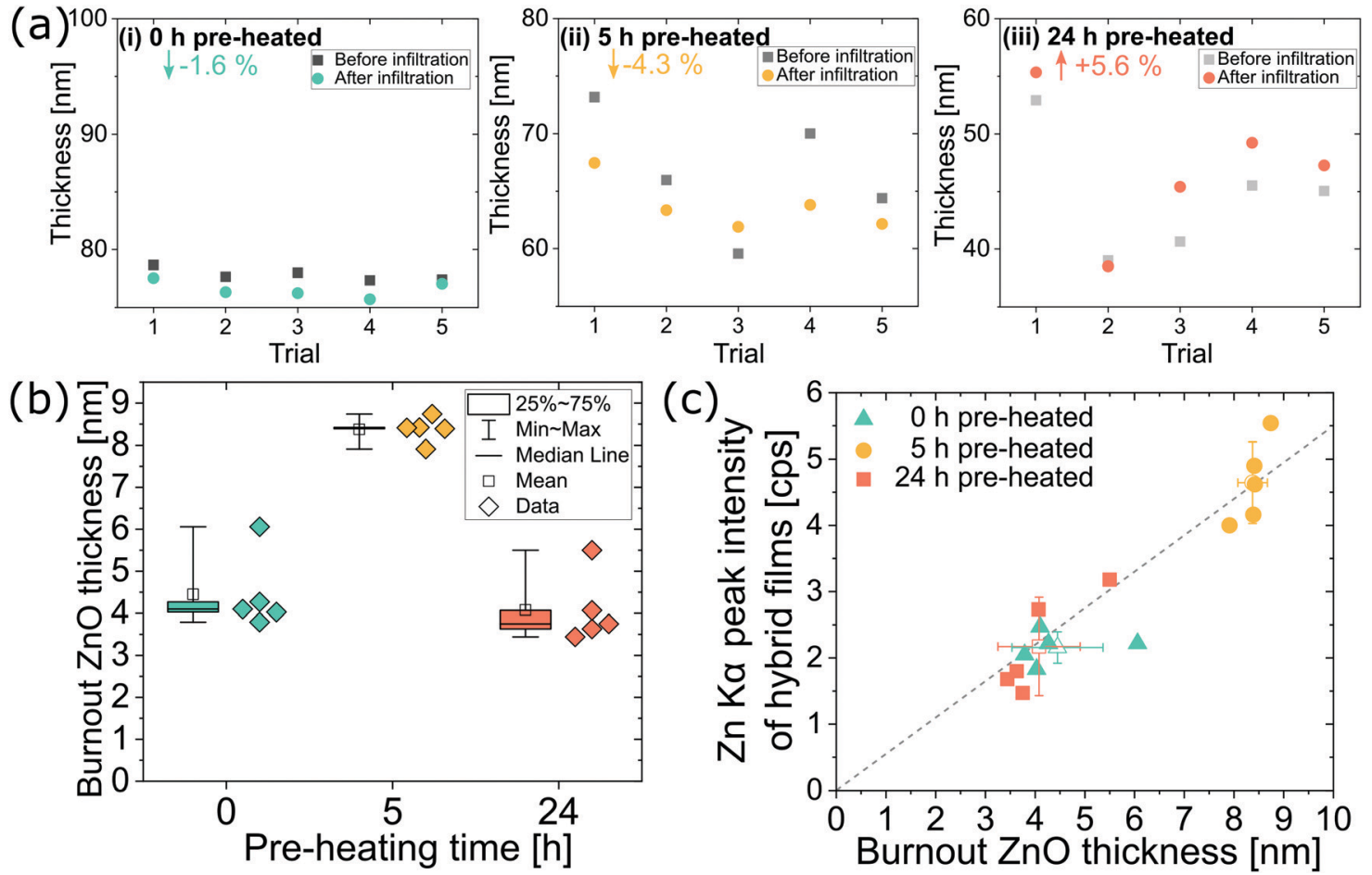

Fig. 3 (a) Thicknesses of cis-polyisoprene films before and after zinc oxide infiltration for 5 separate but equivalent trials. Films were pre-heated at $80{ }^{\circ} \mathrm{C}$ for (i) $0 \mathrm{~h}$, (ii) $5 \mathrm{~h}$, and (iii) $24 \mathrm{~h}$ in air prior to infiltration. (Note the changing abscissa in (i) to (iii) for film thickness but same unit spacing). (b) ZnO film thickness after calcination of the infiltrated films at $650{ }^{\circ} \mathrm{C}$ for $30 \mathrm{~min}$ in air, and (c) correlation of the XRF Zn $\mathrm{K}_{\alpha}$ peak height of the hybrid films and the $\mathrm{ZnO}$ film thickness after calcination; mean values with their standard deviation of the respective data are indicated with open symbols and the linear slope serves as a guide for the eye. All films were infiltrated at $80{ }^{\circ} \mathrm{C}$ using a $7200 \mathrm{~s}, 0.2$ Torr DEZ exposure step.

The inorganic loading increases with increasing hold time until it saturates (for $80{ }^{\circ} \mathrm{C}$ and $100{ }^{\circ} \mathrm{C}$ ). Higher temperatures seem to promote faster saturation (i.e., faster diffusion); in fact, at $60{ }^{\circ} \mathrm{C}$, saturation is not realized within the time scales studied $(4 \mathrm{~h})$. The saturation loading (i.e. maximum solubility) decreases with increasing process temperature. These observations are consistent with the kinetic model for VPI presented by Leng and Losego. $^{28}$ From a derivation of Fick's 2 nd law, the normalized mass uptake $\left(\frac{M_{t}}{M_{\infty}}\right.$, where $M_{\infty}$ is the saturation value) shows a square-root dependence on time $(t)$, with a slope that depends upon the diffusivity $(D)$ and thickness $(L)$ of the polymer matrix

$$
\frac{M_{t}}{M_{\infty}}=\frac{2}{L}\left(\frac{D}{\pi}\right)^{\frac{1}{2}} \sqrt{t}
$$

The diffusivity furthermore follows an Arrhenius relationship

$$
D=D_{0} \exp \left(-\frac{\Delta H_{\mathrm{D}}}{k_{\mathrm{B}} T}\right),
$$

with $D_{0}$ being a temperature independent constant, $\Delta H_{\mathrm{D}}$ the activation energy for diffusion, $k_{\mathrm{B}}$ Boltzmann's constant, and $T$ temperature.

Using these equations and the data presented in Fig. 4(a), we estimate the diffusivity to be about $0.5 \times 10^{-14} \mathrm{~cm}^{2} \mathrm{~s}^{-1}$ and $3 \times 10^{-14} \mathrm{~cm}^{2} \mathrm{~s}^{-1}$ at $80{ }^{\circ} \mathrm{C}$ and $100{ }^{\circ} \mathrm{C}$, respectively. These values are within the same order of magnitude as effective diffusivity values reported for infiltration of trimethylaluminum into poly(methyl methacrylate) ${ }^{28}$ and can give valuable information about infiltration depth when upscaling the process to thicker films or macroscopic objects. ${ }^{8,28}$ Diffusivity values in the order of $10^{-6} \mathrm{~cm}^{2} \mathrm{~s}^{-1}$ have been reported for the diffusion of gas molecules such as $\mathrm{O}_{2}, \mathrm{~N}_{2}$, or $\mathrm{CO}_{2}$ in (vulcanized) natural rubber, i.e. 8 orders of magnitude higher than the current findings; however, it was shown that the diffusivity rapidly decreases with increasing gas molecule size for natural rubber and other polymers. $^{29,30}$ Diffusivity of the much larger DEZ molecule is thus expected to be much lower than for the above mentioned diatomic and triatomic gases.

A close examination of the mass uptake curves for the $5 \mathrm{~h}$ pre-heated cis-polyisoprene films presented in Fig. 4(b) suggests that two separate diffusion regimes may exist (indicated by two linear slopes). For short hold times, precursor can diffuse faster whereas the diffusion slows down for longer hold times (estimates of the diffusivity are given in the ESI $\dagger$ ). A possible reason for this behavior might be ongoing relaxation of polyisoprene films during infiltration, which comes into effect for longer hold times. Furthermore, from FTIR analysis shown in Fig. 2(b), films pre-heated for $5 \mathrm{~h}$ appear to be in a state in which the oxidation is not yet complete. This might lead to the more complex diffusion kinetic curves as the precursor molecules diffuse through both oxidized and unoxidized regions.

For the films pre-heated for $24 \mathrm{~h}$ (shown in Fig. 4(c)), the infiltration kinetics are less differentiable with respect to 

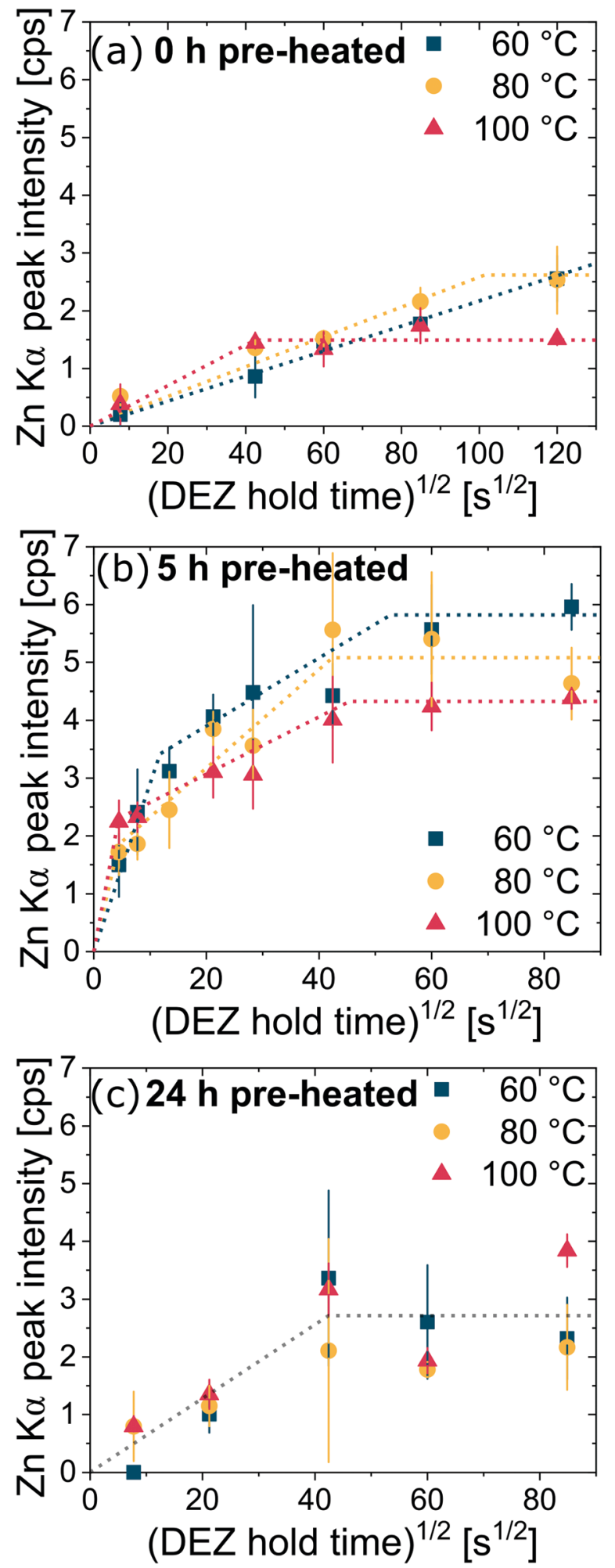

Fig. 4 XRF measurements of zinc uptake after VPI as a function of DEZ exposure time for various process temperatures using cis-polyisoprene thin films pre-heated at $80^{\circ} \mathrm{C}$ in air for (a) $0 \mathrm{~h}$, (b) $5 \mathrm{~h}$, and (c) $24 \mathrm{~h}$. Note the wider ordinate scale for (a). Dotted lines serve as a guide for the eye. Most data points are an average of at least 5 independently processed hybrid films. Error bars represent the standard deviation from measurements on multiple films. temperature. While an increase of loading can be observed by increasing the hold time, the relative changes (between measurements for different temperatures) are rather small and difficult to differentiate within measurement error. A reason might be that on average these films are thinner than the films pre-heated for $5 \mathrm{~h}$ and thus reach full infiltration faster, limiting the temporal resolution of the diffusion process. ${ }^{28}$ However, it appears that for these films only one diffusion regime exists (indicated by an averaged slope), which agrees with the fact that the films were much longer pre-heated prior to infiltration. Also, the maximum loading is on average smaller than for the films pre-heated for $5 \mathrm{~h}$, which can be attributed to the decreased thickness.

\section{E. Entrapment of DEZ precursor in cis-polyisoprene}

Next we explore the entrapment of DEZ precursors within cis-polyisoprene films. Films undergoing $0 \mathrm{~h}, 5 \mathrm{~h}$, and $24 \mathrm{~h}$ pre-heating at $80{ }^{\circ} \mathrm{C}$ were all investigated. Infiltration was conducted at $80{ }^{\circ} \mathrm{C}$ for $800 \mathrm{~s}$ at $\sim 2$ Torr DEZ. Purge times between the DEZ exposure and water exposure were varied between $100 \mathrm{~s}$ and $232200 \mathrm{~s}(\sim 2.5$ days). If the DEZ precursor does not strongly bind to the polyisoprene, $\mathrm{Zn}$ loading should decrease with increasing purge time. ${ }^{31}$ If DEZ forms a permanent or semi-permanent bond to the cis-polyisoprene, then Zn loading should remain nearly invariant with this purge time. As shown in Fig. 5, the latter situation is true, Zn concentration is relatively invariant with purge time irrespective of pre-heating conditions, even up to a purge time of $\sim 2.5$ days. This suggests that the precursor DEZ molecules are strongly bound (entrapped) within the polymer and do not easily diffuse out upon removal of the DEZ overpressure.

To further understand the entrapment mechanisms, ATR-FTIR spectroscopy is used to understand the chemical structure of

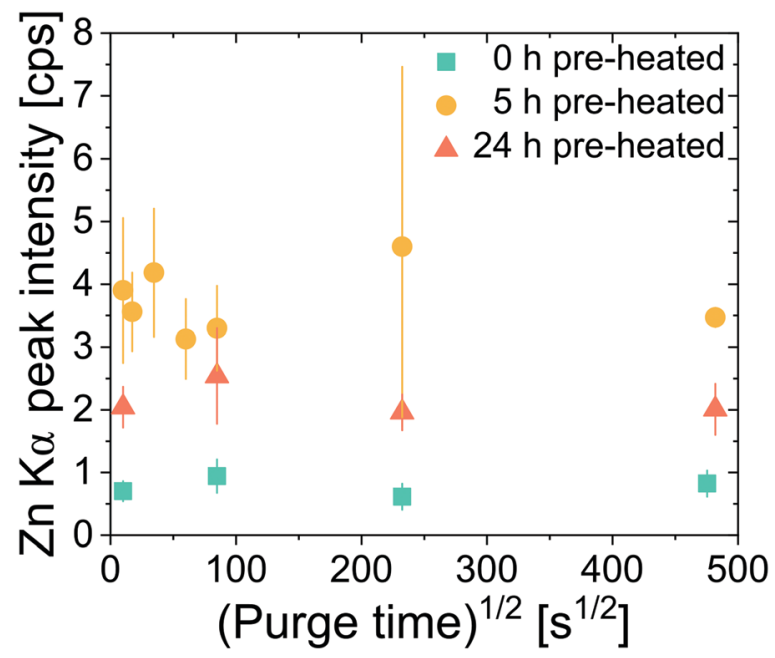

Fig. 5 XRF measurements of zinc concentration in hybrid films as a function of purge time between DEZ exposure and $\mathrm{H}_{2} \mathrm{O}$ exposure. Polyisoprene films are pre-heated at $80{ }^{\circ} \mathrm{C}$ for $0 \mathrm{~h}, 5 \mathrm{~h}$, or $24 \mathrm{~h}$, DEZ hold time is $800 \mathrm{~s}$, and infiltration temperature is $80^{\circ} \mathrm{C}$. Most data points are an average of at least 5 independently processed hybrid films. Error bars represent the standard deviation from measurements on multiple films. 


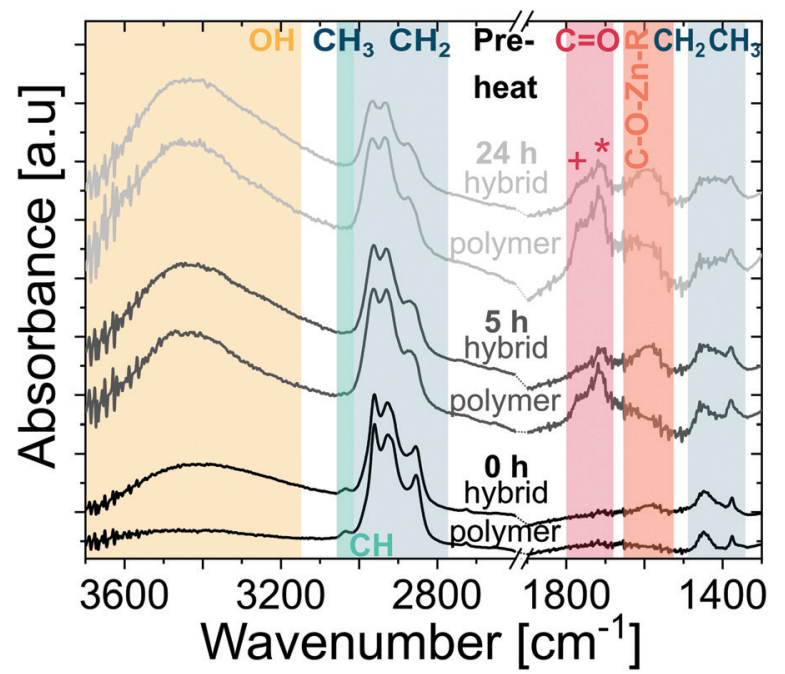

Fig. 6 ATR-FTIR spectra of polyisoprene films before (same data as in Fig. 2(b)) and after infiltration, for polyisoprene films pre-heated at $80^{\circ} \mathrm{C}$ in air for different durations (indicated above the curves) prior to infiltration. Colored regions refer to $\mathrm{O}-\mathrm{H}$ stretching $\left(\sim 3400 \mathrm{~cm}^{-1}\right),=\mathrm{C}-\mathrm{H}$ stretching $\left(\sim 3036 \mathrm{~cm}^{-1}\right), \mathrm{CH}_{3}$ and $\mathrm{CH}_{2}$ stretching $\left(2800-2900 \mathrm{~cm}^{-1}\right), \mathrm{C}=\mathrm{O}$ stretching (+ and * referring to carboxylic acids $\left(\sim 1766 \mathrm{~cm}^{-1}\right.$ ) and ketones $\left(\sim 1714 \mathrm{~cm}^{-1}\right)$, respectively), $\mathrm{C}-\mathrm{O}-\mathrm{Zn}-\mathrm{R}\left(\sim 1550-1650 \mathrm{~cm}^{-1}\right)$, and $\mathrm{CH}_{2}$ and $\mathrm{CH}_{3}$ deformation $\left(1370-1450 \mathrm{~cm}^{-1}\right.$ ). Spectra are scaled to their respective maximum value, offset, and cut to the regions where the main absorptions occur (strong absorption of glass substrate below $1300 \mathrm{~cm}^{-1}$ ). Dotted lines at the axis break serve as a guide for the eye.

the ZnO-polyisoprene hybrid after infiltration. These ATR-FTIR spectra are shown in Fig. 6, together with the spectra of the polyisoprene films before infiltration (from Fig. 2(b)). In comparison to the spectra of pure polymer films, several changes can be observed. The contribution of $\mathrm{O}-\mathrm{H}$ is increased for all films which can be attributed to the water co-reaction in the infiltration process and the likely formation of metal oxyhydroxide inorganic clusters. The reduction in $\mathrm{C}=\mathrm{O}$ peak intensity with DEZ exposure time indicates a consumption of these groups, likely due to chemical reaction with DEZ. For all the hybrid films, a broad absorption emerges at $\sim 1550-1650 \mathrm{~cm}^{-1}$. In VPI literature, this mode has been attributed to metalorganic precursors binding to carbonyl groups, both for $\mathrm{DEZ}^{32}$ and trimethylaluminum. ${ }^{8,33,34}$ This suggests that DEZ entrapment is at least partially explained by binding and reaction with these carbonyl groups, which are not inherent to the pure polyisoprene structure but are rather easily created via pre-heating oxidation. This proposed mechanism is furthermore supported by the analysis of high-resolution XPS spectra of oxygen and carbon (Fig. S5 (ESI $\dagger$ ) and Discussion). However, based on Fig. 5, the unheated polyisoprene also retains constant Zn loading with purging despite having a negligible concentration of carbonyl or hydroxyl groups. This suggest that DEZ molecules can also become permanently or semi-permanently entrapped within the pure cis-polyisoprene polymer. While the Lewisacidic precursor $\mathrm{DEZ}^{35}$ may potentially form an adduct to the alkene functional group, the weak absorption of alkene in IR spectroscopy makes this difficult to ascertain. Thus, further investigations, including a computational investigation and/or in situ spectroscopy are likely necessary.

Upon further inspection of this entire IR data set (see Fig. S6, ESI $\dagger$ ), it appears that the relative intensity of remaining $\mathrm{C}=\mathrm{O}$ groups after infiltration is higher for films pre-heated for a longer duration (see Fig. S6, ESI $\dagger$ ). One explanation is that these groups are inaccessible for reaction with DEZ. A possible reason is that these more oxidized polymers react with more DEZ molecules in the near surface region, creating a dense hybrid near-surface layer that hinders further DEZ diffusion. If true, this process should lead to a non-uniform distribution of inorganic throughout the hybrid layer's thickness. To investigate the distribution of $\mathrm{Zn}$ within the polymer layer, SIMS was performed on a hybrid film that was preheated for $24 \mathrm{~h}$ prior to infiltration. The SIMS depth profile showing $\mathrm{Zn}+, \mathrm{C}+$, and $\mathrm{Si}^{+}$ signals is shown in Fig. 7. The $\mathrm{Zn}$ concentration drops precipitously at about $2 / 3$ of the film's thickness, suggesting that for these conditions it is not evenly distributed across the $\sim 60 \mathrm{~nm}$ hybrid film thickness. Combined with the FTIR data, these results begin to suggest that the greater number of functional groups in the longer pre-heated films lead to a near-surface hybrid layer that significant inhibits diffusion and full infiltration.

Fig. 8 plots the $\mathrm{Zn}$ loading for polyisoprene films pre-heated for different durations. Analyzing these data allows us to partially deconvolute the effects of polymer relaxation from the creation of reactive functional groups due to polymer oxidation. For this purpose, we divide the curve into three regions. In region I, a strong increase in the amount of inorganic loading is observed with increasing pre-heating time. The increase in loading can be related to the creation of functional groups, and the effect is greater than the loss of free volume due to relaxation. In Region II, Zn loading decreases with pre-heating time. As shown in Fig. 2(a), Region II also corresponds to a significant decrease in neat polymer film thickness with pre-heating. This decrease in film thickness is attributed to a loss of free volume, which appears to have a greater effect on the loading than the addition

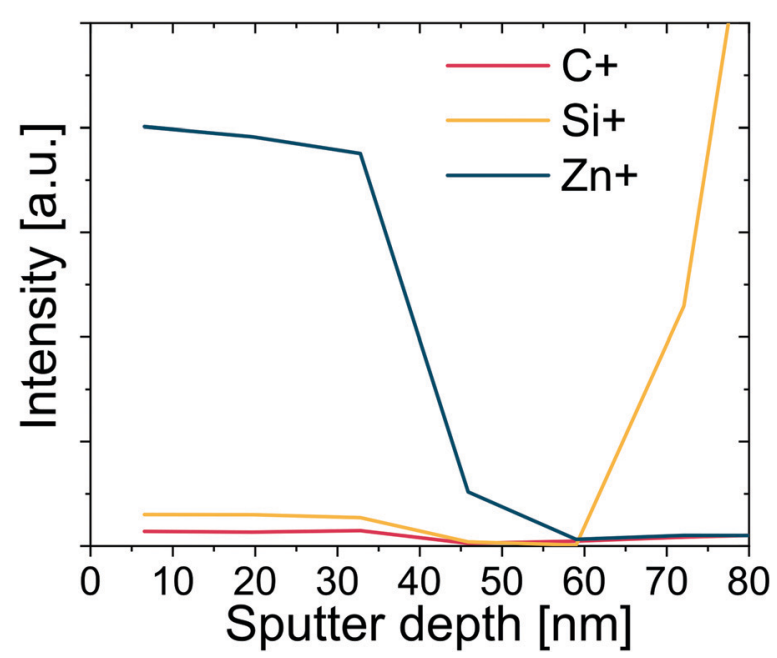

Fig. 7 SIMS profiles for $\mathrm{Zn+}$, Sit, and C+ as a function of sputter depth for an infiltrated polyisoprene films which was preheated for $24 \mathrm{~h}$ at $80{ }^{\circ} \mathrm{C}$ prior to infiltration. 


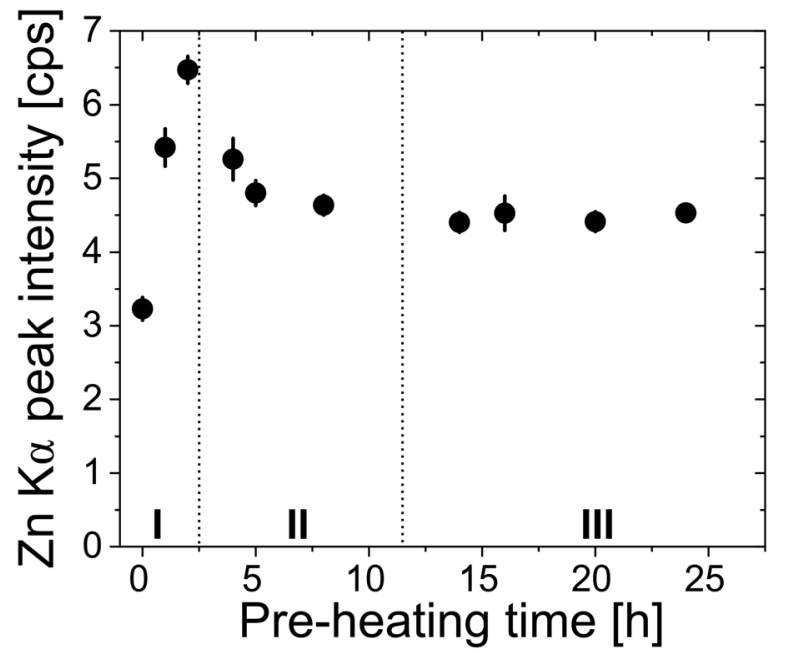

Fig. 8 XRF measurements of zinc concentration in hybrid films as a function of cis-polyisoprene pre-heating time prior to infiltration. General sample size per data point is $n=2$. Error bars represent the standard deviation

of more functional groups, leading to a decrease in $\mathrm{Zn}$ loading. For the longest pre-heating times (Region III), in which both the polymer relaxation and chemical oxidation reach completion (Fig. 2), Zn uptake becomes constant irrespective of pre-heating time. Based on FTIR (Fig. S6, ESI $†$ ) and SIMS (Fig. 7) data, it is likely that films within Region III are also not fully infiltrated. Instead, these films only have a saturated near-surface layer, likely of similar thickness dictated by the high concentration of reactive functional groups. It is also possible that the decrease in Zn loading in region II could be a combination of lower free volume and reduced infiltration due to the blocking layer. In fact, the fast and then slow diffusion regimes of Fig. $4 \mathrm{~b}$ may be indicative of these different contributions to the inorganic loading process.

Fig. 9 provides a schematic sketch summarizing our current understanding of the mechanisms controlling DEZ/ZnO entrapment in polyisoprene polymers as a function of pre-heating time. The infiltration of unheated polyisoprene films results in a small to modest amount of loading. While the DEZ is permanently entrapped, the exact chemical bonding mechanism is not known. Increasing pre-heating times lead to relaxation of the polyisoprene

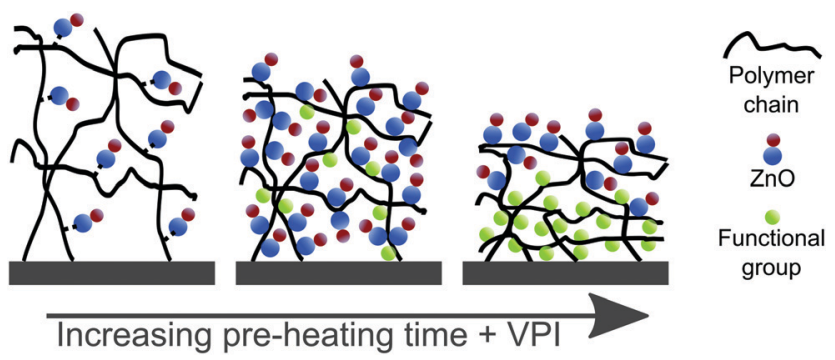

Fig. 9 Schematic of $\mathrm{ZnO}$ loading into polyisoprene as a function of polymer pre-heating time. Pre-heating is believed to affect both the concentration of functional groups reactive to DEZ and the free volume in the polymer. film and increased loading due to creation of functional groups through oxidation. Further increase of pre-heating time leads to further relaxation and dense loading in the top of the film. This dense hybrid layer blocks further sorption and diffusion of the precursor, leaving uninfiltrated regions at the bottom of the film.

\section{F. Dissolution of ZnO-polyisoprene hybrid films}

Dissolution experiments are performed to better understand the physicochemical structure of the ZnO-polyisoprene hybrid materials. Hybrids are tested against toluene because it is a good solvent for the neat cis-polyisoprene polymer. Fig. 10 plots the normalized thickness as a function of immersion time for (a) pure polyisoprene polymers pre-heated for $0 \mathrm{~h}, 5, \mathrm{~h}$ and $24 \mathrm{~h}$ and (b) infiltrated ZnO-polyisoprene hybrids formed from these various preheated conditions.

Polyisoprene polymers (Fig. 10(a)) rapidly lose thickness upon immersion in toluene. All films show a loss of at least $40 \%$ in thickness within 30 min of immersion. The unheated

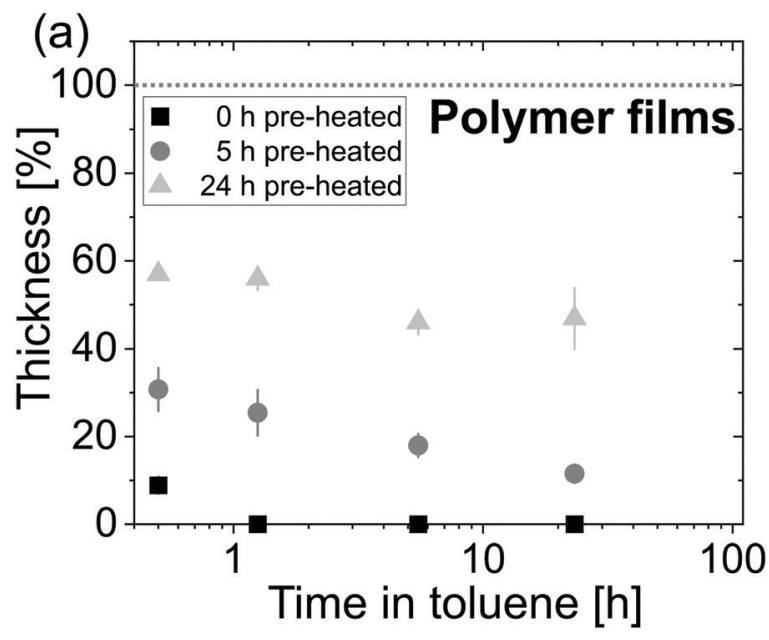

(b)

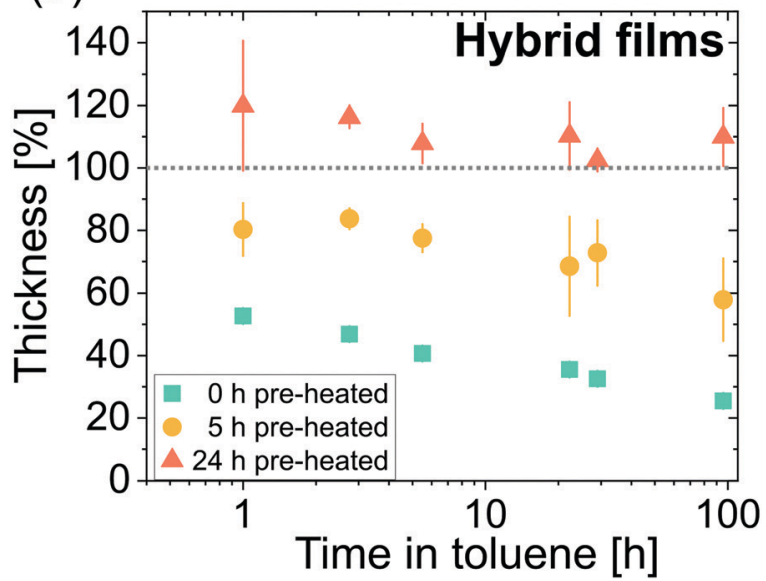

Fig. 10 Normalized film thickness of (a) pure and (b) infiltrated polyisoprene films as a function of time in toluene. Polyisoprene films were preheated for either $0 \mathrm{~h}, 5 \mathrm{~h}$, or $24 \mathrm{~h}$ prior to (a) dissolution or (b) infiltration and dissolution. Dotted lines indicate normalized film thickness (100\%) prior to immersion in toluene. Sample size per data point $n=2$. Error bars represent the standard deviation from measurements on multiple films. 
neat polymer dissolves most rapidly and is completely dissolved within $1 \mathrm{~h}$. Neat polymers that are pre-heated prior to immersion in toluene show increased stability. The $5 \mathrm{~h}$ heated film loses around $90 \%$ of thickness within $25 \mathrm{~h}$, but at least $50 \%$ of the $24 \mathrm{~h}$ heated film survives for $25 \mathrm{~h}$ of immersion. This stability is likely the result of oxidative cross-linking. ${ }^{22}$

Infiltration of the films leads to increased stability for all pre-heating conditions. Unheated film and films pre-heated for $5 \mathrm{~h}$ do show some dissolution but at a much slower rate than the pure polymer films. Films which are pre-heated for $24 \mathrm{~h}$ prior to infiltration swell upon immersion (normalized thickness exceeds $100 \%$ ). This result suggests that these hybrid materials are likely chemically cross-linked. For $5 \mathrm{~h}$ pre-heating, this cross-linking is probably incomplete. For unheated films, precursors may not be bound to the polymer at all, and rather act to simply inhibit polymer reptation and simply slow the dissolution rate.

The ability to increase chemical stability of polymers in solvents by VPI has been reported for different systems. ${ }^{8,15}$ In a recent study by McGuinness et al., ${ }^{8}$ the stability of $\mathrm{AlO}_{x}$-poly(methyl methacrylate) hybrid films was tested in various solvents. The authors found that the infiltration temperature controlled the physicochemical structure of the final hybrid material and its resultant chemical dissolution performance. Low infiltration temperatures led to unbound inorganic in the polymer matrix whereas high temperatures led to chemical bonds between the precursor and the moieties of the polymer as well as crosslinking. Films infiltrated at high temperatures were found to be stable in all investigated solvents whereas films infiltrated at low temperature showed dissolution in some solvents, including dissolution of the inorganic in water. While the effect of infiltration temperature on dissolution behavior was not part of this study, we observe similar trends via the introduction of chemically reactive functional groups through polymer oxidation. Longer pre-heating times lead to the creation of more functional groups in the polymer with which the precursor can chemically react. These chemical reactions lead to more cross-linking that increase chemical stability.

\section{Conclusions}

This study demonstrates the ability to use single-exposure vapor phase infiltration of DEZ $+\mathrm{H}_{2} \mathrm{O}$ on cis-polyisoprene polymers to create ZnO-polyisoprene hybrid materials. Unlike other VPI chemistries, volume changes (i.e., film thickness changes) with infiltration are not well correlated to inorganic mass loading. Volume changes appear to be a convolution of polymer relaxation processes (reduced volume) and mass uptake (volume expansion processes) that are often similar in magnitude. XRF spectroscopy is introduced as an alternative non-destructive method for quantifying the amount of inorganic loading in these hybrid films. Several complicating factors are identified in controlling the infiltration process of polyisoprene rubbers. Both changes in the free volume of the polymer and the potential to oxidize the polymer and form reactive carbonyl and hydroxide groups at modest temperatures $\left(80{ }^{\circ} \mathrm{C}\right)$ contribute to the DEZ sorption, diffusion, and entrapment processes. With modest heating and oxidation of the polymer, it is possible to significantly increase the zinc oxide loading by more than $2 \times$. IR spectroscopy confirms reaction with these oxidized functional groups, revealing both a decrease in the carbonyl intensity and the emergence of a $\mathrm{C}-\mathrm{O}-\mathrm{Zn}-\mathrm{R}$ functional group. However, continued heating of the polymer decreases $\mathrm{Zn}$ loading. This decrease is attributed to either a decrease in the polymer's free volume or a highly cross-linked near surface layer that prevents further sorption and diffusion, the latter appearing to be more likely. Interestingly, even without these oxide functional groups, the DEZ appears to form a stable adduct within the polymer that is highly resistant to desorption, even without dosing the water co-reactant. However, the resulting hybrid films show significantly different dissolution behavior in toluene, a good solvent for the pure polymer. Infiltrated polyisoprene with negligible functional groups dissolves, albeit slowly, while infiltrated polyisoprene with many reactive functional groups shows much more limited dissolution or even swelling as would be expected for a cross-linked gel. These observations suggest distinct differences in the chemical bonding structure of these organic-inorganic hybrid materials. Further computational studies or in situ process characterization will be necessary to fully understand this behavior, however, significant opportunity exists in exploring these infiltrated hybrid materials as new accelerators for rubber vulcanization or modifiers to alter the physical properties of polyisoprene rubbers.

\section{Conflicts of interest}

There are no conflicts of interest to declare.

\section{Acknowledgements}

This project has received partial funding from the European Research Council (ERC) under the European Union's Horizon 2020 research and innovation program (Grant Agreement No. 715403). This material is also based upon work partially supported by the National Science Foundation under Grant \# 1921873. J. P. acknowledges personal funding from the Austrian Marshall Plan Foundation for funding his research stay at Georgia Tech. This work was performed in part at the Georgia Tech Institute for Electronics and Nanotechnology, a member of the National Nanotechnology Coordinated Infrastructure, which is supported by the National Science Foundation (Grant ECCS-1542174). The authors acknowledge Yi Li for performing XPS measurements, Jamie P. Wooding for performing SIMS measurements, and Yulian Yao for AFM measurements. Any opinions, findings, and conclusions or recommendations expressed in this material are those of the authors and do not necessarily reflect the views of these funding agencies.

\section{References}

1 M. Morton, Rubber Technology, Van Nostrand Reinhold Company Inc, New York, 3rd edn, 1987.

2 K. Roy, S. C. Debnath and P. Potiyaraj, J. Elastomers Plast., 2020, 52, 167-193. 
3 S. Mostoni, P. Milana, B. Di Credico, M. D'Arienzo and R. Scotti, Catalysts, 2019, 9, 664.

4 G. Heideman, R. N. Datta, J. W. M. Noordermeer and B. van Baarle, J. Appl. Polym. Sci., 2005, 95, 1388-1404.

5 M. Knite, V. Teteris, A. Kiploka and J. Kaupuzs, Sens. Actuators, A, 2004, 110, 142-149.

6 Y. Ikeda and S. Kohjiya, Polymer, 1997, 38, 4417-4423.

7 V. S. Raman, A. Das, K. W. Stöckelhuber, S. B. Eshwaran, J. Chanda, M. Malanin, U. Reuter, A. Leuteritz, R. Boldt, S. Wießner and G. Heinrich, RSC Adv., 2016, 6, 33643-33655.

8 E. K. McGuinness, C. Z. Leng and M. D. Losego, ACS Appl. Polym. Mater., 2020, 2, 1335-1344.

9 R. P. Padbury and J. S. Jur, Langmuir, 2014, 30, 9228-9238.

10 H. I. Akyildiz, R. P. Padbury, G. N. Parsons and J. S. Jur, Langmuir, 2012, 28, 15697-15704.

11 R. Z. Waldman, D. J. Mandia, A. Yanguas-Gil, A. B. F. Martinson, J. W. Elam and S. B. Darling, J. Chem. Phys., 2019, 151, 190901.

12 A. Subramanian, N. Tiwale and C.-Y. Nam, JOM, 2019, 71, 185-196.

13 S.-M. Lee, E. Pippel, U. Gosele, C. Dresbach, Y. Qin, C. V. Chandran, T. Brauniger, G. Hause and M. Knez, Science, 2009, 324, 488-492.

14 W. Wang, F. Yang, C. Chen, L. Zhang, Y. Qin and M. Knez, Adv. Mater. Interfaces, 2017, 4, 1600806.

15 E. K. McGuinness, F. Zhang, Y. Ma, R. P. Lively and M. D. Losego, Chem. Mater., 2019, 31, 5509-5518.

16 D. H. Yi, C.-Y. Nam, G. Doerk, C. T. Black and R. B. Grubbs, ACS Appl. Polym. Mater., 2019, 1, 672-683.

17 C. Z. Leng and M. D. Losego, Mater. Horizons, 2017, 4, 747-771.

18 D. R. Burfield and K. L. Lim, Macromolecules, 1983, 16, 1170-1175.
19 B. D. Piercy and M. D. Losego, J. Vac. Sci. Technol., B: Nanotechnol. Microelectron.: Mater., Process., Meas., Phenom., 2015, 33, 043201.

20 K. A. M. dos Santos, P. A. Z. Suarez and J. C. Rubim, Polym. Degrad. Stab., 2005, 90, 34-43.

21 R. A. Saunders and D. C. Smith, J. Appl. Phys., 1949, 20, 953-965.

22 X. Colin, L. Audouin and J. Verdu, Polym. Degrad. Stab., 2007, 92, 886-897.

23 J. L. Morand, Rubber Chem. Technol., 1977, 50, 373-396.

24 M. Zaghdoudi, A. Kömmling, M. Jaunich and D. Wolff, Polymers, 2019, 11, 1280.

25 T. Sato, K. Sakota, M. Egami, K. Shirano and T. Okaya, J. Appl. Polym. Sci., 1977, 21, 981-988.

26 G.-Y. Li and J. L. Koenig, Rubber Chem. Technol., 2005, 78, 355-390.

27 Y. Li, M. Kröger and W. K. Liu, Polymer, 2011, 52, 5867-5878.

28 C. Z. Leng and M. D. Losego, Phys. Chem. Chem. Phys., 2018, 20, 21506-21514.

29 G. J. Van Amerongen, Rubber Chem. Technol., 1951, 24, 109-131.

30 A. R. Berens and H. B. Hopfenberg, J. Membr. Sci., 1982, 10, 283-303.

31 E. Cianci, D. Nazzari, G. Seguini and M. Perego, Adv. Mater. Interfaces, 2018, 5, 1801016.

32 W. Xie, S. Khan, O. J. Rojas and G. N. Parsons, ACS Sustainable Chem. Eng., 2018, 6, 13844-13853.

33 G. T. Hill, D. T. Lee, P. S. Williams, C. D. Needham, E. C. Dandley, C. J. Oldham and G. N. Parsons, J. Phys. Chem. C, 2019, 123, 16146-16152.

34 E. C. Dandley, C. D. Needham, P. S. Williams, A. H. Brozena, C. J. Oldham and G. N. Parsons, J. Mater. Chem. C, 2014, 2, 9416-9424.

35 X. Ye, J. Kestell, K. Kisslinger, M. Liu, R. B. Grubbs, J. A. Boscoboinik and C.-Y. Nam, Chem. Mater., 2017, 29, 4535-4545. 